\title{
Characterization tools for shrinkage-compensating repair materials
}

\author{
Benoît Bissonnette ${ }^{1, *}$, Samy-Joseph Essalik ${ }^{1}$, Charles Lamothe ${ }^{1}$, Marc Jolin $^{1}$, Luc Courard ${ }^{2}$, Richard Gagné ${ }^{3}$, and \\ Richard Morin ${ }^{4}$ \\ ${ }^{1}$ CRIB, Department of Civil Engineering, Laval University, Québec (QC), G1V 0A6, Canada \\ ${ }^{2}$ Urban and Environmental Engineering, ArGEnCo Dept., University of Liège, Allée de la découverte 9, B-4000, Liège, Belgium \\ ${ }^{3}$ CRIB, Department of Civil Engineering, University of Sherbrooke, Sherbrooke (QC), J1K 2R1, Canada \\ ${ }^{4}$ City of Montreal, 999 rue De Louvain, Montréal (QC), H2M 1B3, Canada
}

\begin{abstract}
Achievement of dimensional compatibility is one of the most important considerations in order to consistently achieve lasting repair works that do not undergo harmful cracking. Drying shrinkage of Portland cement concrete is generally inevitable and, although its magnitude can be reduced by optimizing or modifying the composition parameters, it remains significantly larger than its ultimate tensile strain. Conversely, the use of shrinkage-compensating concrete $(\mathrm{ShCC}$ ) may allow to achieve a zero-dimensional balance with respect to drying shrinkage, through the use of a mineral expansive agent. The experimental work carried out in recent years at Laval University to evaluate the potential of shrinkage-compensating concretes $(S h C C)$ for use as repair materials has in fact yielded quite promising results. Nevertheless, more research is required to turn $S h C C$ systems into a truly dependable and versatile repair option. Among the issues still unresolved, suitable tests methods must be developed, not only to better characterize $S h C C$, but also to guide the specifications and perform field quality control. Efforts have thus been devoted to adapt or develop test procedures intended to better capture the particular volume change behavior of ShCC's. The paper presents two test procedures intended to assess the shrinkage-compensating potential and the effective strain balance of $S h C C$ in restrained conditions.
\end{abstract}

\section{Introduction}

Achieving dimensional compatibility is among the greatest challenges with regards to concrete repair materials. In the process of selecting the right repair material, Emmons [1] stated that drying shrinkage is a critical factor and that whenever possible, repair materials subject to as low as possible drying shrinkage should be opted for. Drying shrinkage of Portland cement concrete is generally inevitable and, although its magnitude can be reduced by optimizing or modifying the composition parameters, it remains significantly larger than its ultimate tensile strain.

Conversely, the use of shrinkage-compensating concrete $(S h C C)$ may allow to achieve a zero dimensional balance with respect to drying shrinkage, through the use of a mineral expansive agent [2]. During hydration, the expansive agent reaction induces expansive forces within the cement paste, leading to a net macroscopic volume increase. When the material is exposed to drying, shrinkage gradually offsets the initial expansion, resulting in a close-to-zero dimensional balance if the expansive agent content is properly adjusted. In restrained movement conditions, when the drying shrinkageinduced stresses exceed the material tensile strength, cracks occur the repair. In the case of $S h C C$, the expansion induces a compressive stress in the early stages of hydration (chemical prestress), which is then progressively relieved by the drying shrinkage that occurs as soon as the material is exposed to a lower relative humidity. This prevents or at least limits the development of net tensile stresses in the repair material, and thereby reduces the risk of cracking.

Shrinkage-compensating materials made with an expansive mineral admixture thus represent an attractive option to prevent shrinkage cracking in concrete repairs.

\section{Background}

While expansive binders or components are being used in the development of various proprietary repair materials, mainly thin-layer mortars labeled as shrinkagecompensating or even sometimes non-shrink [3], their use in the formulation of batch plant repair concretes is virtually nonexistent. Provided that strong bond is achieved, such that the essential development of the chemical prestress can actually take place, ShCC shows a a lot of potential in the repair industry, as noted in previous studies [4-9].

* Corresponding author: benoit.bissonnette@gci.ulaval.ca 
More broadly, these systems can provide a very effective solution to shrinkage cracking problems in concrete construction in general. For obscure reasons, outside the field of industrial flooring, their use remains somewhat limited. Yet, erratic expansion problems (duration, intensity) that had been occasionally encountered in the past and that can adversely affect the durability have been resolved and the overall properties of ShCC favorably compare to those of ordinary concrete made with cement Portland [10]. Besides, the initial expansion of $S h C C$ can be further controlled by using supplementary-cementing materials [7, 11-12] or fibers [13].

As emphasized by Ramseyer and Roswurm [14], the primary reference in North America for proper use of shrinkage compensating systems is still the ACI 223R-10 Guide for Use of Shrinkage Compensating Concrete [15] This document provides general guidance concerning the mechanical behavior of ShCC under restraint, notably acknowledging that in a structural member without external restraint, the required ASTM C878 [16] restrained expansion value increases with the amount of steel reinforcement. Such guiding statement is fundamentally based on pioneer experimental work by Russell [17], which forms the basis for the ShCC reinforcement design recommendations found in ACI 223R-10.

In the days the aforementioned data were generated, shrinkage-compensating concretes (ShCC) were essentially made with ASTM type K cement. Today, they are most generally prepared with the addition of an expansive component to Portland cement during the mixing operations, either calcium sulfoaluminate-based (type K) or calcium oxide-based (type G) [15]. Other expansive components, for instance magnesia, are gaining interest for producing ShCC. Unfortunately, the performance of current shrinkage-compensating concrete materials under mechanical restraint (either internal or external) is not well documented [14].

These components behave differently at the microstructural level and, accordingly, can impact quite differently the macroscopic behavior of the ShCC concrete elements, depending on the binder type and composition, the moisture availability (w/cm, curing), the level of restraint, etc.

Other important reasons call for the need to revisit the reference graphs developed by Russell [17-18]. The linear relationship assumed in these graphs between ASTM C878 [16] test results and the corresponding net expansion undergone by a structural member for with a given reinforcement ratio - irrespective of the member size - needs to be investigated more thoroughly. The curves are linear extrapolations from single data points and likely underestimates time-effects such as creep. Besides, the graphs address only the expansive phase of ShCC. Is this enough to ensure that the long-term net strain balance is satisfactory? Could shrinkage be influenced by the expansion? To answer these questions, investigation of the drying shrinkage phase is necessary.

In the current practice of $S h C C$, the only specific standard test procedure being used is ASTM C878, which is a lightly restrained length change test. As part of the test protocol, only the expansive phase (moist curing condition) is monitored, until the age of 7 days. Test procedures need to be reconsidered to better capture what matters ultimately with respect to cracking sensitivity: the overall longer-term strain balance.

In order to exploit advantageously the unique features of $S h C C$ as repair materials, and even as general purpose concretes, the incidence of the expansion-shrinkage and the restraint conditions must be studied in depth.

\section{Context}

The experimental work carried out in recent years at Laval University to evaluate the potential of shrinkagecompensating concretes $(S h C C)$ for use as repair materials has yielded quite promising results. $S h C C$ repair material effectiveness and robustness were evaluated in depth as a function of selected parameters, using the two main types of expansive agents in use today, type $\mathrm{K}$ and type $\mathrm{G}$ with different binders. The assessment of robustness addressed the influence of both the mixture design variables (cement composition, expansive agent type and rate of addition) and the curing conditions (water availability, temperature) upon $S h C C$ 's expansive behavior, the bond between $S h C C$ and an existing concrete substrate, and $S h C C$ 's durability. The research work accomplished so far has demonstrated the effectiveness of $S h C C$, both the type K and type G agents being effective in compensating the drying shrinkage of different binder systems (Portland cement, silica fume, slag), with adequate curing conditions (moisture, temperature) [4-5]. In summary, it was found that ShCC can be frost resistant, that pre-stressing generated by simple adhesion between an ShCC overlay and the old concrete substrate can be sufficient to achieve the required amount of compensation in a repaired element such as to prevent cracking, and that the effect of the initial expansion is not harmful to the bond strength development between the two materials. Their effectiveness was further assessed in different experimental bridge repair projects in the Montreal area [19]. After more than ten years of exposure in some cases, the portions of these structures repaired with $S h C C$ concretes still did not exhibit any surface cracking.

\section{Scope}

Additional work is required to turn $S h C C$ systems into a truly dependable and versatile repair option. Among the issues still unresolved, the engineering behind the shrinkage compensation design process for repairs has yet to be developed and better documented. The overall influence of the different expansive systems and their effectiveness with a variety of cement/binder systems needs to be investigated in depth. The findings will provide a basis for optimizing specifications, detailing, as well as construction practice (repair thickness, bonding or anchoring, material selection, curing technique and duration, etc.) of $S h C C$ repairs. Ultimately, the findings are expected to benefit the overall concrete construction industry towards sustainability. 
In that quest, an important aspect that needs to be addressed is the lack of suitable tests methods to characterize $S h C C$, to guide the specifications and to perform QA/QC. Efforts have been devoted recently at CRIB to adapt or develop test procedures intended to better capture the particular behavior of $S h C C$ 's.

\section{Methodological development}

This paper reports essentially on the development of test procedures better adapted to capture the particular volume change behavior of $S h C C$ 's. In the current practice, ASTM C878 is the only standard test procedure being used and it fails to address some important aspects. The specific objectives of this effort are the following: 1) to modify the ASTM C878 procedure to cover both the expansion and drying shrinkage phases and allow to evaluate the net long-term strain balance; 2 ) to investigate the use of a modified ring test procedure for $S h C C$ for evaluating the strain balance and the risk of cracking.

\subsection{ASTM C878 modified}

The ASTM C878 test method covers the determination of length changes of expansive cement concrete, while under restraint, due to the development of internal forces resulting from the expansive reaction occurring during the early stages of hydration of the cement. The test specimen is a $76.2 \times 76.2 \times 254 \mathrm{~mm}$ concrete prim cast within a steel cage, consisting of a threaded low-carbon steel rod (diameter $=4.76 \mathrm{~mm}$ ) with $76.2 \times 76.2 \times 9.53 \mathrm{~mm}$ steel end plates held in place by nuts. The specimens are removed from the molds at the age of $6 \mathrm{~h}$ or as soon as practicable. The initial comparator reading is taken 30 minutes after demolding. After the initial comparator reading, the specimens are cured in lime-saturated water at $23^{\circ} \mathrm{C}$ until they have reached an age of 7 days. At the end of the curing period, another comparator reading is taken. Comparator readings can be taken at intermediate ages between the initial and 7-day readings, such as to assess the expansion kinetics (not mandatory).

As explicitly suggested in the ASTM C878 standard, the test was adapted to study conditions that differ from the standard procedure. Hence, the test setup was modified to test ShCC's under different degrees of restraint, and to evaluate the information that could be lost with the first reading being taken at the age of 6 to 9 hours.

To modify easily the degree of restraint and allow the monitoring of early deformations with strain-gage mounted rods, a plastic sleeve (17.8 $\mathrm{mm}$ in diameter) isolating the rod from the surrounding concrete was added to the restraining cage (Fig. 1). The layout departs slightly from the standard test, where the rod is not only restrained by the end plates, but also through adhesion/friction with the surrounding concrete. The proposed modification has the advantages of fixing the concrete cross-sectional area, irrespective of the size of the retraining rod being used, and providing some space for the strain gage wires when using instrumented rods (Fig. 1b).
In the modified test procedure, restraining rods with the following diameters can be used: $4.76 \mathrm{~mm}, 7.14 \mathrm{~mm}$, $9.53 \mathrm{~mm}$ and $12.70 \mathrm{~mm}$.

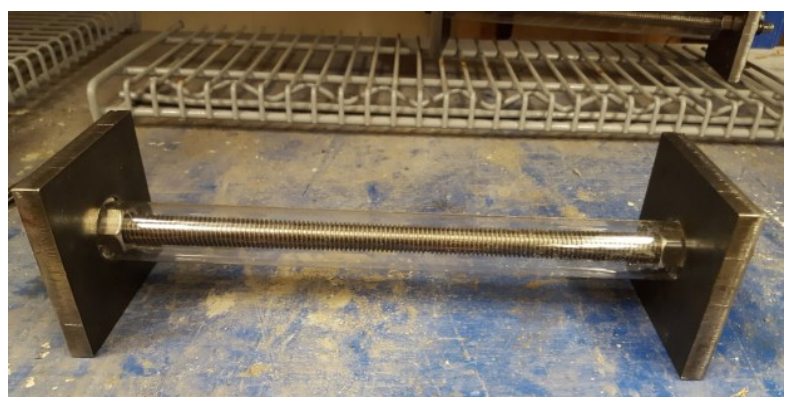

a) Non-instrumented rod

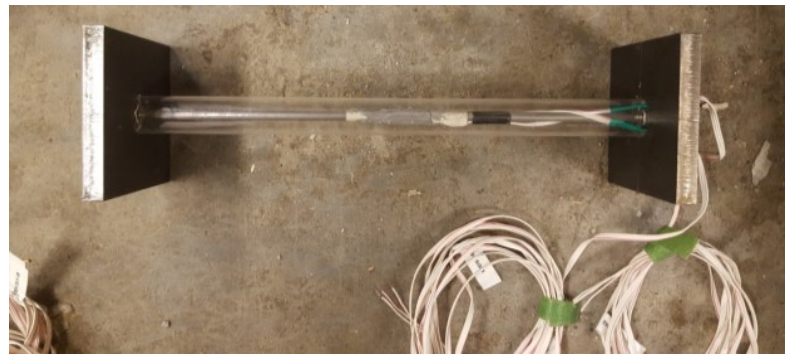

b) Strain-gage mounted rod

Fig. 1. Restraining cage used in the modified ASTM C878 test procedure.

\subsection{AASHTO T334 modified}

The AASHTO T334 (formerly PP34) method covers the determination of the cracking tendency of concrete when restrained [20]. The test method basically measures the strain development in a steel ring as a surrounding concrete ring shrinks against it.

The method is not suitable to test materials undergoing early expansion, as the concrete ring initially detaches from the inner restraining ring and the restraining effect gets close to none for a certain period of time, theoretically until the strain balance in the concrete ring becomes negative (i.e. contraction overcoming the expansion).

Based on the AASHTO T334 test, a restrained expansion annular test has been developed at CRIB, the main difference being the use of an outer steel ring instead of an inner ring (same thickness, different radius). Hence, in the modified procedure (Fig. 2), a concrete ring having the exact same geometry as in the AASHTO test is cast inside a steel ring with the same thickness $(12,5 \mathrm{~mm})$. Instead of being instrumented with strain gages on its inner face, the steel ring used in the restrained expansion test is instrumented on its outer face.

Another difference with the AASHTO T334 procedure is the use of a companion specimen to measure the free deformation in parallel with that of the restrained ring. Two specimen geometries have been used and compared to the results obtained in the commonly used ASTM C157 test [21]: a concrete ring with the same dimensions as the restrained specimen and a prismatic specimen with the same cross-section as the ring and a length of $304.8 \mathrm{~mm}$. Sealing of the specimens was 
performed in such a way to obtain the same volume to surface $(\mathrm{V} / \mathrm{S})$ ratio in all cases.

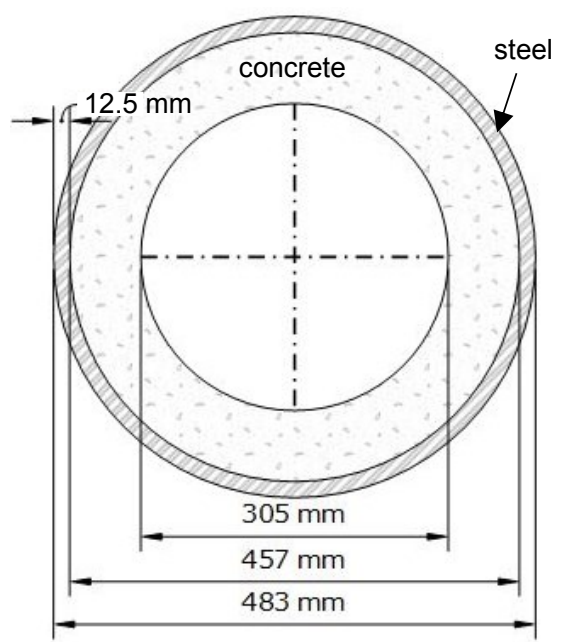

Fig. 2. AASHTO T334 test procedure modified to test expansive materials (ring height: $152 \mathrm{~mm}$ ).

\section{Experimental data generated with the new test procedures}

To demonstrate the type of results generated with the newly developed test procedures, series of tests have been carried out using a basic shrinkage-compensating repair concrete mixture prepared with a $\mathrm{w} / \mathrm{cm}$ ratio of 0.50 and $15 \%$ of type K component.

\subsection{ASTM C878 modified test results recorded from the time of casting}

An important consideration when evaluating the length change behavior of concrete incorporating expansive cement is the time at which the measurements begin. In the standard ASTC C878 test, the initial comparator readings are generally performed between 6.5 and 9 hours after the initial water-cement contact, which means that significant early information may be lost. In the modified procedure, rods instrumented with strain gages can be used to monitor the deformations from the time of casting up to the time of initiating the comparator readings (note: the use of strain gages is not extended to the moist curing period, because of the inherent difficulty associated with moist curing). The data recorded for the four restraining levels during the initial curing period in the molds are displayed in Figure 3. The experimental curves show that up to 6 to 10 hours, the volume changes for the tested ShCC are relatively low. It appears that for a type K-based system, the procedure relying solely on comparator readings starting when the specimens can be stripped from their molds captures satisfactorily the meaningful deformations. It must be stressed that the situation might be different with other expansive systems, for instance a type $\mathrm{G}$ component.

\subsection{ASTM C878 modified test results from the time of specimen stripping}

The ASTM C878 modified test results are presented in Figure 4 . In addition to the five reinforcement ratios from 0 to $2,40 \%$, the graph also shows the comparative result obtained for the standard ASTM C878 specimen. As expected, the expansion reached at 7 days in the test specimens decreases with an increasing reinforcement ratio.

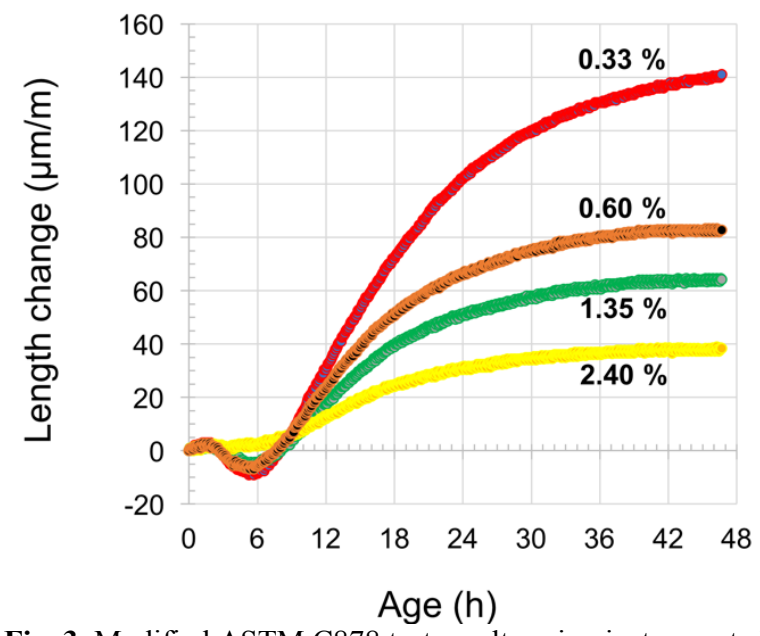

Fig. 3. Modified ASTM C878 test results using instrumented restraining rods (ShCC: $15 \%$ type K comp.; w/cm $=0.50$ ).

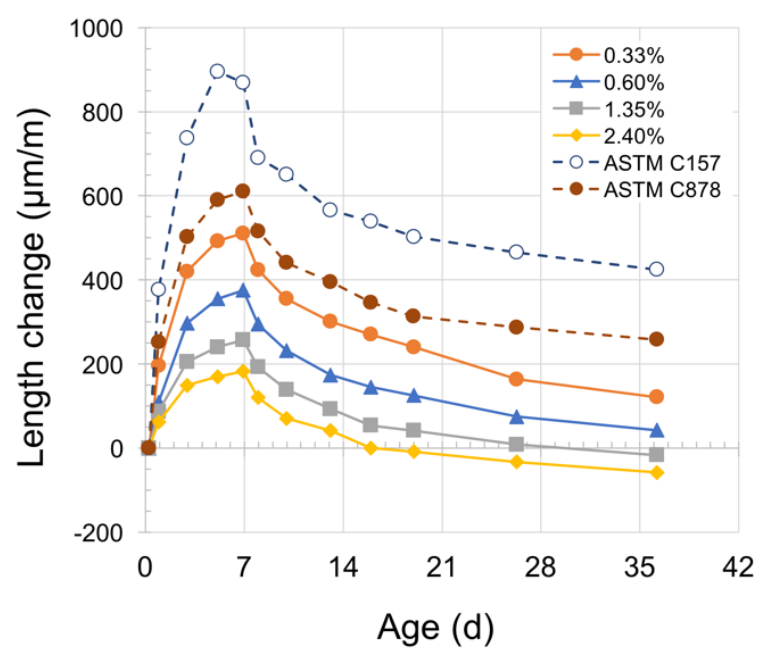

Fig. 4. Modified ASTM C 878 test results (ShCC: $15 \%$ type K comp.; $\mathrm{w} / \mathrm{cm}=0.50$ ).

The portion of the curve beyond 7 days, i.e. the drying phase, is not monitored in the standard ASTM C878 procedure. As can be seen in Figure 4, the relative magnitude of the early expansion and subsequent contraction varies as a function of the reinforcement ratio. After 28 days of drying, the average net strain balance in the unreinforced specimens is still largely positive, whereas in specimens with reinforcement ratios of 1.35 and $2.40 \%$, it is already negative. Would the concrete be strictly elastic and non-ageing, the net strain would simply decrease in proportion with the reinforcement ratio, both during the expansion and shrinkage stages. However, it is not the case, as concrete becomes stiffer with ageing and 
undergoes creep under loading. Monitoring both the expansion and drying periods is necessary to validate and quantify the shrinkage compensating capability of a $S h C C$ mixture, depending on the reinforcement ratio. It is necessary for a more in-depth analysis, which may include a detailed analysis of the various strain components, as illustrated in Figure 5.

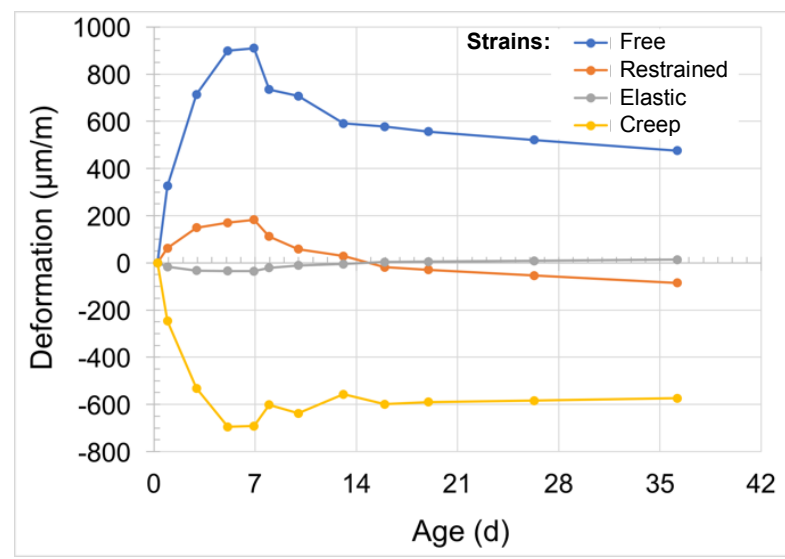

Fig. 5. Determination of the various strains in the total deformation recorded in the modified ASTM C878 test (ShCC: $15 \%$ type $\mathrm{K}$ comp.; w/cm $=0.50$ ).

The basic tool in North America to design a ShCC mixture depending on the reinforcement ratio and the type of expansive system (type $\mathrm{K}$, type $\mathrm{G}$ ) is a graph similar to the one presented in Figure 6. In that figure, the relationship found between the ASTM C878 modified data the standard ASTM C878 data are superimposed to the reference curves found in ACI 223R-10 for ASTM type K cement. Some differences can be observed, which may relate to the nature of the sulfoaluminates responsible for the expansion, as well as to their concentration (amount of expansive agent in the cement paste).

The ACI 223 graphs, both for type K and type $G$ components, need to be revisited in depth, notably taking into account the rate of addition in expansive agent and the $\mathrm{w} / \mathrm{cm}$ value. In addition, their use must also be reconsidered to better address to notion of strain balance in ShCC mixture design.

\subsection{Modified AASHTO T334 test results}

The result obtained for the investigated $S h C C$ mixture in the modified AASHTO T334 test are displayed in Figure 7. As expected, with a degree of restraint significantly higher than that of the series with the highest reinforcement rate in the modified ASTM C878 procedure, the restrained expansion if further reduced, reaching at 7 days barely $5-6 \%$ of the corresponding free expansion (see Fig. 4). As a result, the chemical prestress is exhausted after slightly more than 7 days. Still, the shrinkage compensation is comparable to that of the ASTM C878 modified specimens with a reinforcement ratio of $2.40 \%$.

In view of evaluating the respective contributions of the various types of deformations in the restrained ring, as shown in the example of Figure 5 for the ASTM C878 modified test, it is necessary to measure the free deformation on a companion specimen. The comparative free deformation curves obtained on ring and prismatic specimens having the same volume-to-surface ratio (V/S) are shown in Figure 8. As found in other test series by the authors, the sealing of ASTM C157 specimens to yield the same $\mathrm{S} / \mathrm{V}$ is not enough and the data overestimates the actual ring deformations. On the contrary, data generated with a prismatic specimen having the same crosssectional area and similar exposure (sealed / unsealed faces) are very close to those recorded from annular specimens (within the test variability). From a practical point of view, the use of prismatic companion specimens obviously eases the procedure.

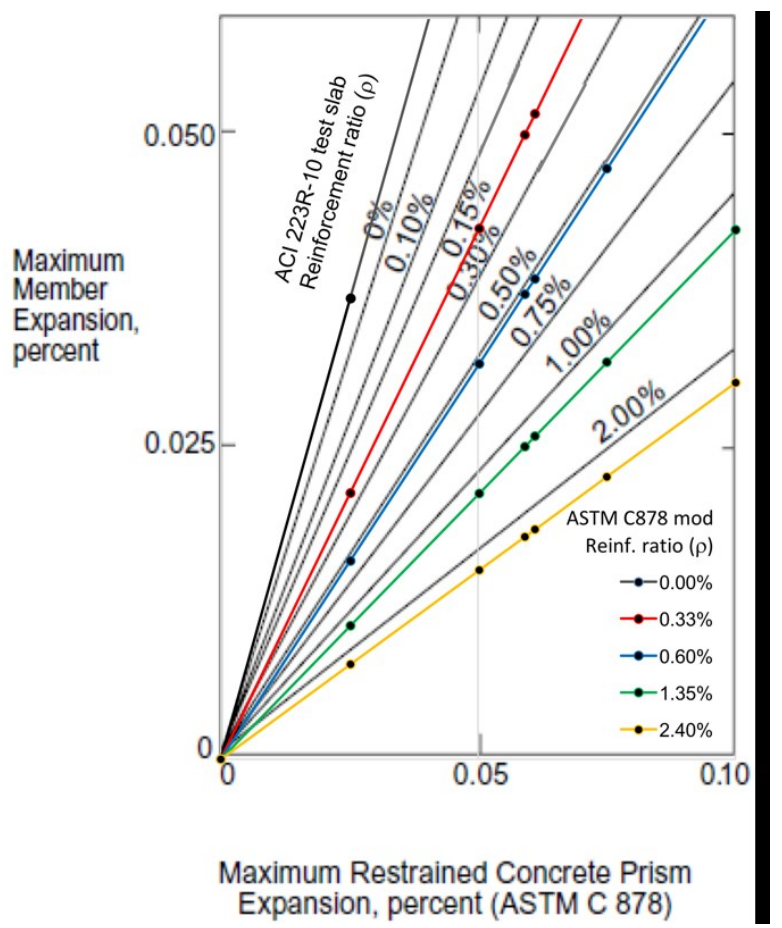

Fig. 6. ACI 223R-10 graph for ASTM type K cement with the experimental data $(S h C C: 15 \%$ type K comp.; w/cm $=0.50)$.

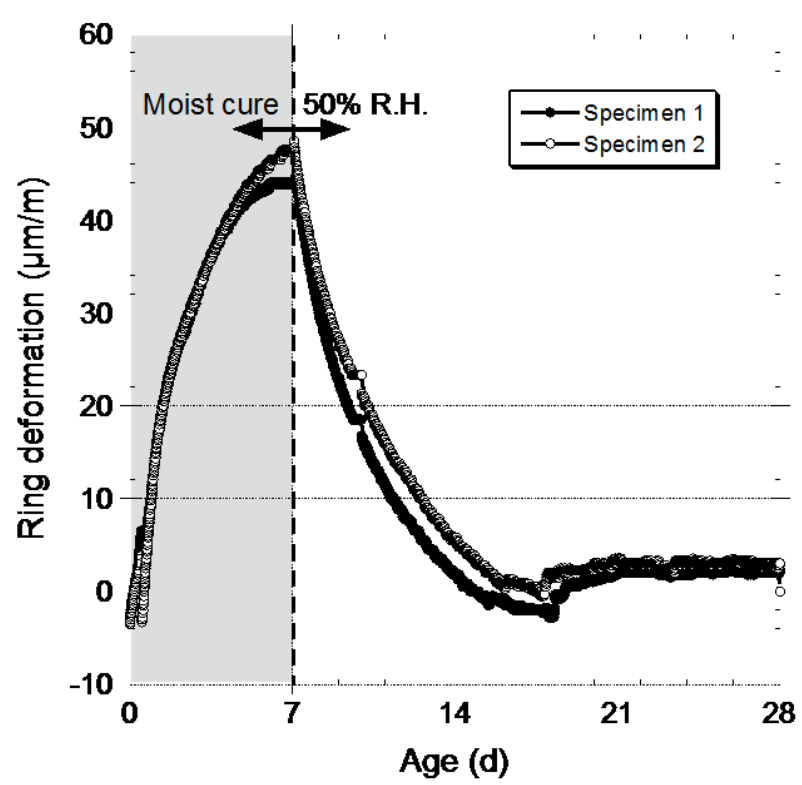

Fig. 7. Modified AASHTO T334 restrained deformation test results $($ ShCC: $15 \%$ type K comp.; w/cm = 0.50). 


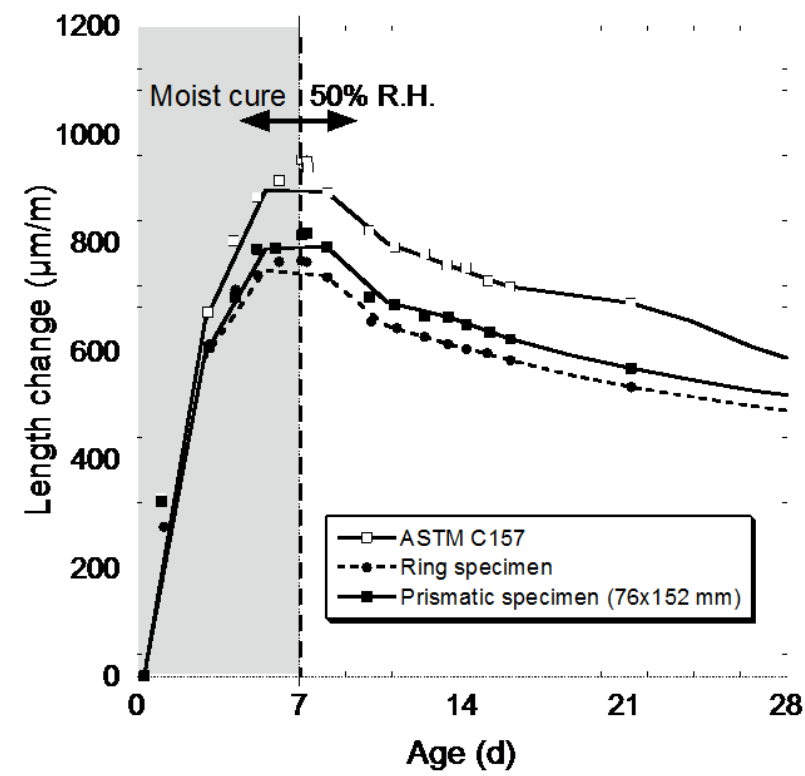

Fig. 8. Comparative free deformation data recorded for companion specimens with various geometries (ShCC: 15\% type $\mathrm{K}$ comp.; $\mathrm{w} / \mathrm{cm}=0.50$ ).

\section{Conclusion}

The testing procedures presented herein, namely an ASTM C878 modified test and AASHTO T334 modified tests, were developed with the intent of better characterizing the volume changes and chemical prestressing process of $S h C C$. The test methods will be beneficial towards material developments, design refinement, adapted specifications and suitable QC/QA. In the short-term, the more urgent tasks in view of optimizing the use of $S h C C$, in repairs as well as in other applications, are the following:

- Reconsidering the design approach based on the longterm free shrinkage of the concrete mixture without expansive agent / cement;

- Evaluating the use of ASTM C878 to assess the strain balance after drying at 50\% R.H.;

- Assessing the adequacy of recording initial readings at $6 \mathrm{~h}$ or as soon as practicable, for the different expansive systems available;

- Characterizing the ultimate compensating potential of the various expansive systems, taking into account parameters such as the type of cement and the w/cm value, through the use of the modified ASTM C878 restrained expansion test and the modified AASHTO T334 ring test;

- Revisiting the ACI 223 design graphs for both type K and type $\mathrm{G}$ components, evaluating the influence of parameters such as the type of cement and the $w / \mathrm{cm}$ value;

- Developing design graphs for other expansive systems, such as magnesia;

- Establishing a basis for shrinkage-compensating concrete specifications and QA/QC.

This project has been financially supported by the Natural Sciences and Engineering Research Council of Canada
(NSERC) and the Québec FQ-RNT Research Fund. The authors wish to express their gratitude to Mr. Mathieu Thomassin and René Malo for their contribution to the experimental work.

\section{References}

1. P.H. Emmons, Concrete Repair and Maintenance Illustrated, R.S. Means Co., 295 p. (1994)

2. B. Bissonnette, F. Perez, S. Blais, R. Gagné, Évaluation des bétons à retrait compensé pour les travaux de réparation, Can. J. Civ. Eng., 35(7), 716726 (2008)

3. ACI 364.15T-18, Significance of the shrinkagecompensating and nonshrink labels on packaged repair materials, Am. Conc. Inst., 5 p. (2018)

4. P.-V. Certain, B. Bissonnette, J. Bastien, J. Marchand, M. Jolin, Robustness of shrinkagecompensating repair concretes, Innovative Materials and Techniques in Concrete Construction, ACES Workshop Proc., 291-301 (2012)

5. B. Bissonnette, M. Jolin, R. Gagné, P.-V. Certain, F. Perez, Evaluation of the robustness of shrinkagecompensating concrete repair concretes prepared with expansive components, ACI SP-307-08, 18 p. (2016)

6. R.W. Cusick, C.E. Kesler, Final summary report: behavior of shrinkage-compensating concretes suitable for use in bridge decks, U. of Illinois UC, Report no. 165, 33 p. (1977)

7. Z. Bayasi, R. Abifaher, Final summary report: behavior of shrinkage-compensating concretes suitable for use in bridge decks, Conc. Int., 14, 4, 3537 (1992)

8. K.A. Herr, R.T. Barclay, Use of type $K$ expansive cement concrete for new construction and rehabilitation of concrete bridge decks, Proc. of the Materials Engineering Conference, Infrastructure: New Materials and Methods of Repair, 804, 955-962 (1994)

9. M. Krol, Strategy of rehabilitation of concrete structures in energetics by using of expansive materials, Prace Naukowe Instytutu Budownictwa Politechniki Wroclawskiej, 70, 23, 127-134 (1998)

10. A.M. Neville, Wither expansive cement?, Conc. Int., 16, 9, 34-35 (1994)

11. C. Lobo, M.D. Cohen, Hydration of type K expansive cement paste and the effect of silica fume: II. Pore solution analysis and proposed hydration mechanism, Cem. Conc. Res., 23, 1, 104-114 (1993)

12. K.J. Folliard, M. Ohta, E. Rathje, P.P. Collins, Influence of mineral admixtures on expansive cement mortars, Cem. Conc. Res., 24, 3, 424-432 (1994)

13. B.K. Paul, M. Polivka, E. Rathje, P.K. Mehta, Properties of fiber reinforced shrinkagecompensating concrete, ACI J., 78, 6, 488-492 (1981)

14. C. Ramseyer, S. Roswurm, Behavior of type $K$ shrinkage compensating concrete under various forms of mechanical restraint, ACI SP-307-03, Am. Conc. Inst., 18 p. (2016)

15. ACI 223.R-10, Guide for the use of shrinkagecompensating concrete, Am. Conc. Inst., 16 p. (2010) 
16. ASTM C878-Standard test method for restrained expansion of shrinkage-compensating concrete ASTM Int., 5 p. (2014)

17. H.G. Russell, Design of shrinkage-compensating concrete slabs, Klein Symposium on Expansive Cement Concretes, ACI SP-38, Am. Conc. Inst., 193226 (1973)

18. H.G. Russell, R.A. Stadler, H.G. Gelhardt III, Shrinkage-compensating concrete made with an expansive component, Conc. Int., 24, 8, 107-111 (2002)
19. R. Gagné, B. Bissonnette, M. Thibault, R. Morin, Innovative concrete overlays for bridge-deck rehabilitation in Montréal, Proc. of the $2^{\text {nd }}$ International Conference on Concrete Repair, Rehabilitation and Retrofitting (ICCRRR II), Cape Town, South Africa, 351 (2008)

20. AASHTO T334-08-Standard method of test for estimating the cracking tendency of concrete, Am. Ass. State Hwy Transp. Off., 6 p. (2016)

21. ASTM C157-Standard test method for length change of hardened hydraulic-cement mortar and concrete, ASTM Int., 7 p. (2014) 